\title{
ZOOTECNIA BRASILEIRA: QUARENTA ANOS DE HISTÓRIA E REFLEXÕES
}

\section{Brazilian Zootechny: forty years of bistory and thought}

\author{
"Fiat justitia, ruat caelum...". \\ "Non vi, virtute". \\ ("Faça-se justiça ainda que o céu venha abaixo...". \\ "Não pela força, mas pelo mérito.")
}

Walter Motta Ferreira ${ }^{1}$ Severino Benone Paes Barbosa ${ }^{2}$ Célia Regina Orlandelli Carrer ${ }^{3}$ Francisco Fernando Ramos de Carvalbo ${ }^{4}$ Ruy Alberto Caetano Corrêa Filho ${ }^{5}$ Wilson Moreira Dutra Júnior ${ }^{6}$ Rilke Tadeu Fonseca de Freitas ${ }^{7}$ Bruno de Souza Mariano ${ }^{8}$ Edimar Mesquita de Oliveira ${ }^{9}$ Ronaldo Lopes Oliveira ${ }^{10}$ José Paulo de Oliveira ${ }^{11}$ João Waine Pinheiro ${ }^{12}$ Marcos Elias Traad da Silva ${ }^{13}$

1 Prof. Dr. Universidade Federal de Minas Gerais, Escola de Veterinária, Departamento de Zootecnia, Av. Antônio Carlos, n. 6627, Pampulha, CEP 30161-970 - Belo Horizonte, MG - Brasil - Caixa-Postal: 567, telefone: (31) 34992204, fax: (31) 34992168, e-mail: waltermf@vet.ufmg.br.

2 Prof. Ph.D. Universidade Federal Rural de Pernambuco, Departamento de Zootecnia, R. Dom Manoel de Medeiros, s/n, Dois Irmãos, CEP 52171-900 - Recife, PE - Brasil, telefone: (81) 33206550, fax: (81) 33206551, e-mail: sbarbosa@dz.ufrpe.br.

3 Prof. Dr. Universidade de São Paulo, Faculdade de Zootecnia e Engenharia de Alimentos de Pirassununga, Departamento de Ciências Básicas, R. Duque de Caxias Norte, 225 - ZAB/FZEA/USP, Centro, CEP 13635-000 - Pirassununga, SP - Brasil - Caixa-Postal, 23, Telefone: (19) 3565-4052 Fax: (19) 3561-8606, e-mail: recarrer@usp.br

4 Prof. Dr. Universidade Federal Rural de Pernambuco, Departamento de Zootecnia, Av. Dom Manoel de Medeiros, s/n Dois Irmãos, CEP 52171-900 - Recife, PE - Brasil, telefone: (81) 3320-6025, Fax: (81) 3320-6026, e-mail: ffr.carvalho@dz.ufrpe.br.

5 Prof. Dr. Universidade Federal de Mato Grosso do Sul, Centro de Ciências Biológicas e da Saúde, Departamento de Produção Animal, Av. Felinto Muller, 2443 - Núcleo de Ciências Veterinárias, Câmpus Universitário, CEP 79070900 - Campo Grande, MS - Brasil - Caixa-Postal: 549, telefone: (67) 3453625 Ramal: 3625 Fax: (67) 3453600, e-mail: correaf@nin.ufms.br.

6 Prof. Dr. Universidade Federal Rural de Pernambuco, Departamento de Zootecnia, Curso de Zootecnia, R. Dom Manuel de Medeiros, s/ n, Dois Irmãos, CEP 52171-900 - Recife, PE - Brasil, Telefone: (81) 3320-6550 Ramal: 6570 Fax: (81) 3320-6551, e-mail: dutrajr@ufrpe.br.

7 Prof. Dr. Universidade Federal de Lavras, Departamento de Zootecnia / UFLA, Câmpus Universitário, CEP 37200000 - Lavras, MG - Brasil - Caixa-Postal: 3037, telefone: (35) 3829-1230 Fax: (35) 3829-1231, e-mail: rilke.freitas@pesquisador.cnpq.br.

8 Prof. M.Sc. Universidade Católica de Goiás, Zootecnia, Av. Universitária nº 1440, St. Universitário, CEP 74605010 - Goiânia, GO - Brasil, telefone: (62) 3946-1714 Fax: (62) 3946-1715, e-mail: mariano@cultura.com.br.

9 Prof. Adjunto II CCA/UFPB - Câmpus de Areia, Rodovia BR 079 - km 12, Areia - Paraîba - Brasil- Câmpus II - Areia - PB, e-mail: edimar@cca.ufpb.br.

10 Prof. Dr. Universidade Federal da Bahia, Escola de Medicina Veterinária, Departamento de Produção Animal, Av. Ademar de Barros, 500, Lab. de Nutrição Animal, Ondina, CEP 40170-110 - Salvador, BA - Brasil, Telefone: (71) 3263-6716, e-mail: ronaldooliveira@ufba.br.

11 Prof. Dr. Universidade Federal Rural do Rio de Janeiro, Instituto de Zootecnia, Departamento de Produção Animal, Antiga Rodovia Rio - São Paulo, km 47 (Rod BR 465, km 7, Universidade, CEP 23980000 - Seropedica, RJ - Brasil, Telefone: (21) 2682-1063 Fax: (21) 26821063, e-mail: jpaulo@email.com.br.

12 Prof. Dr. Universidade Estadual de Londrina, Departamento de Zootecnia, Rodovia Celso Garcia Cid (PR445) km 380, Câmpus CEP 86051990 - Londrina, PR - Brasil - Caixa-Postal: 6001, Telefone: (43) 3371-4475 Fax: (43) 371-4079, e-mail: jwaine@uel.br.

13 Prof. Dr. Instituto Agronômico do Paraná, Diretoria Técnico Científica, Área de Nutrição Animal, Estrada da Graciosa, km 18 - Parque Castelo Branco, CEP 80011-970 - Curitiba, PR - Brasil - Caixa-Postal: 2031, telefone: (41) 3665-6336 Ramal: 218 Fax: (41) 3665-6979, msilva@smma.curitiba.pr.gov.br. 


\section{Resumo}

A criação do primeiro curso de Graduação em Zootecnia no Brasil, pela Pontifícia Universidade Católica do Rio Grande do Sul, na Cidade de Uruguaiana, deu-se aos treze de maio de um mil e novecentos e sessenta e seis, sob fortes protestos de outras profissões que, à época, eram as responsáveis pela produção animal. Nesses quarenta anos de existência, as ações dos Zootecnistas e o crescimento das suas entidades de representação profissional evidenciam várias contribuições para o avanço do negócio agrícola no Brasil, tornando a profissão cada vez mais reconhecida pela sociedade. Como profissão relativamente nova no contexto daquelas que compreendem as Ciências Agrárias, a Zootecnia procurou estabelecer-se ao longo do tempo, debatendo e promovendo a sua consolidação diante de um cenário relativamente hostil, com disputas em condição de desigualdade com os grupamentos profissionais mais antigos ou majoritários, face às distorções da legislação que rege a sua atuação no mercado de trabalho. Assim, este relato apresentado por Zootecnistas procura recuperar e analisar fatos, promovendo a reflexão sobre a breve história profissional e de lutas passadas nos últimos 40 anos e a síntese do melhor que pode proporcionar a Zootecnia para o desenvolvimento do País. Para tanto, o documento está composto por eixos temáticos que discorrem sobre os pensamentos e fatos registrados, entendidos como os mais relevantes para a compreensão da trajetória histórica da Zootecnia edificada como ciência e profissão no Brasil, incluindo as características do seu ensino de graduação, bem como reflete, em parte, a agenda política atual para a profissão, orientada pela Associação Brasileira de Zootecnistas (ABZ).

Palavras-chave: Zootecnistas; Associações profissionais; Associação de zootecnistas; Ciências agrárias.

\section{Abstract}

The first Zootechny college course in Brasil was carried on by Catholic University, at Rio Grande do Sul, Uruguaiana City, on May thirteen ninety sixty six, against many others profession groups that was the ones witch works on animal production at that time. During this forty years, the Zootechnists works and the development of his professional representatives, have been demonstrating important contributions for the Brazilian agribusiness, promoting the society profession recognition and importance. As one of the youth group on the Agrarian Sciences Professions, the Zootechny have been building their basis along the time, discussing and promoting your fundamental basis, fighting on a unequal scenario, considering other oldest majority professions and the legal legislation problems and distortions that rules it's acting on works market. Therefore, this report presented by Zootechnists, try to rescue and analyze facts, aiming to promote reflections about the professional fighting history on the last 40 years, and the best contributions that the Zootechny could present for the Country. For this purpose, the document is composed by thematic axis that strolls around registered thoughts and facts understood as the main important for the real comprehension of the Zootechny trajectory, build as a science and profession at Brazil, including it's teaching characteristics and the current policy agenda for the profession, oriented by the Brazilian Zootechnists Association (ABZ).

Keywords: Zootechnists; Professional association; Zootechnists association; Agrarian sciences.

\section{Introdução}

Pode-se considerar que há pouco mais de 50 anos de distância entre o que germinou das mãos de Octávio Domingues, o Patrono da Zootecnia brasileira, e o que a Zootecnia apresenta nos dias de hoje. Meio século de lutas, estudos, escárnios, injustiças, debates, muitas ausências, indiferenças e algumas glórias conquistadas no descuido dos céticos.

O mote usado no nascedouro da Zootecnia como profissão era "Tudo pela Zootecnia". Um chamado que embutia uma charmosa arrogância mesclada com doses generosas de esperança da novidade que surgia. Um rugido de defesa e de criação de um espaço próprio.
Impuseram-se algumas condições para que Octávio Domingues fincasse a bandeira da Zootecnia no cume pretendido. Algumas dessas condições foram expedidas pela autocracia de exceção ligada aos interesses de corporações profissionais predominantes.

O tempo passou e os Zootecnistas continuaram gritando o "Tudo pela Zootecnia", fazendo-se valer da força incontida nessa expressão. Passou Octávio Domingues no começo dos anos de chumbo e, com ele, foi sepultada a parte inicial da história que se seguiu com a luta que se esperava vencer. Mas qual luta e por qual vitória esperavam os Zootecnistas? 
Anteriormente, o argumento de edificação de uma nova profissão na paisagem agrária brasileira se baseava nas possibilidades de desenvolvimento dos vastos campos de pastagens e da bovinocultura dos trópicos. Entretanto, as novas regras de consumo foram impostas pelas fortes tendências do fantasmagórico e invisível Mercado e ao atendimento das exigências dos mais ricos. Exportar tornou-se palavra de ordem para expressar o que importa.

Pode ser típico e pouco engenhoso simplesmente dizer: o mundo mudou! Mas e a Zootecnia mudou? Foi levada pela mudança ou colabora com as transformações? O "Tudo pela Zootecnia" significava um ponto de partida, um lance de efeito, um urro para dizer: olhe como somos grandes! Ou: como podemos ficar grandes!

Bem melhor dito, o "Tudo pela Zootecnia" era um convite a uma aposta. Um clamor momentâneo à Sociedade para que no futuro esta mesma Sociedade pudesse referendar que a aposta foi gratificante e com bons resultados. Mas este tempo de apostas já passou e talvez algo tenha se esparramado pelo caminho e que precisa ser recuperado.

Quem dirá que a Zootecnia é bem-vinda é o povo brasileiro! É a sociedade brasileira que referendará este apoio técnico nos complexos negociais dos produtos e serviços na produção animal. Quem reconhecerá a importância da Zootecnia será esta mesma sociedade, que só agora está percebendo que algo acima de 33\% do Produto Interno Bruto refere-se ao negócio agrícola, lato sensu.

Não basta dizer que os Zootecnistas foram perseguidos, excluídos, massacrados por outros grupamentos profissionais que pelejam por uma fatia daquilo para o que a Zootecnia foi feita. É preciso servir com apreço e seriedade se aproximando muito mais das necessidades das comunidades e populações, para que estas possam julgar o futuro, pelos benefícios que são proporcionados com as ações destes profissionais.

É urgente que haja mais compromissos e mais cumplicidade dos profissionais Zootecnistas por um país melhor, induzindo com esforço a percepção de qualquer cidadão ao seu alcance. É preponderante a organização e a identificação dos Zootecnistas como parceiros da opção pela vida com qualidade e para todos. É necessária a associação ao processo de desenvolvimento com os de- mais segmentos e categorias profissionais que labutam na mesma vertente.

A Zootecnia é arte e ciência, com dinâmica suficiente para computar complexidade notável a cada dia que passa. Entretanto, não está só, nem é dona isolada do espaço que se circunscreve no mercado produtivo. O mercado existe per se e sobreviverá com ou sem a Zootecnia pretendida pelos Zootecnistas. No entanto, importa fazer valer a participação deste grupamento profissional como ciência, com a produção de conhecimentos e na sua relevância técnica e social.

Quem sabe o que foi perdido pelo caminho da história foi o gesto mais simples de poder compartilhar dificuldades e debilidades diante da grandeza imposta do "Tudo pela Zootecnia"? Quem sabe agora que as luzes insistem em brilhar, os Zootecnistas possam entender mais do que nunca que é necessária uma nova ordem, ou seja: "Todos pela Zootecnia"?

O relato apresentado estabelece a tentativa de recuperação de fatos, análises e reflexões produzidas por Zootecnistas preocupados em relatar para a Sociedade como um todo, nas suas diferentes formas de representação política e jurídica, a breve história profissional e de lutas nos últimos 40 anos e a síntese do melhor que pode proporcionar a Zootecnia para o desenvolvimento do País. Assim posto, este documento é uma tentativa que procura reunir o significado e as referências das aspirações dos profissionais Zootecnistas, sob a ótica da liberdade, da justiça e da verdade, as conquistas tão almejadas por esta categoria profissional.

O documento está composto por eixos temáticos que discorrem sobre os pensamentos e fatos registrados, entendidos como os mais relevantes para a compreensão da trajetória histórica da Zootecnia edificada como ciência e profissão no Brasil, incluindo as características do seu ensino de graduação, bem como reflete, em parte, a agenda política atual.

Zootecnia Brasileira, Quarenta Anos de História e Reflexões é um documento elaborado por Zootecnistas pela Zootecnia, cuja verdade histórica, expressão de idéias e a vontade política são consolidadas e aprovadas nos fóruns e reuniões de âmbito nacional de Zootecnistas e de entidades da Zootecnia, sob a liderança da Associação Brasileira de Zootecnistas (ABZ). 


\section{Redefinindo zootecnia}

\section{A zootecnia e o bomem}

No desenvolvimento das sociedades humanas, as mudanças que acontecem nas relações entre os homens e entre esses com a natureza originam, condicionam e determinam a divisão das ocupações em inúmeros e diferentes ofícios. Esses ofícios, por suas vezes, podem receber a sanção social como profissões utilizando-se normalmente da escola, do instituto, da faculdade ou universidade, instituições criadas pela mesma sociedade, que sistematizam de maneira a dar visibilidade aos conhecimentos que agenciam. Em conseqüência, é possível acompanhar o surgimento de inúmeros ofícios e profissões tidas como de nível superior nas condições sociais que facilitaram sua criação, as leis que regulamentam seu exercício e, principalmente, os elementos acadêmicos estruturais desenvolvidos pelas instituições de ensino que formam profissionais capacitados a exercer funções que são próprias ao seu campo do saber ou à sua área de conhecimento. São inúmeros os relatos da literatura onde se registram casos que mostram estas situações. Durante a revolução neolítica, por exemplo, o surgimento da agricultura, e com ela uma economia baseada na produção de alimentos, originou grupos humanos relativamente especializados quanto ao plantio, o cuidado com os animais ou a realização de atividades mistas, nos quais, aliás, apresentou indícios de uma atribuição do trabalho baseada em ofícios dirigidos à divisão sexual dos membros das comunidades.

No que diz respeito às atividades pecuárias, a situação não teria por que ser diferente. $\mathrm{Na}$ idade tardia do bronze, ao norte da Síria e Mesopotâmia, existiram grupos humanos dedicados a treinar e cuidar de cavalos. Além disso, houve tentativas para sistematizar os conhecimentos quanto ao manejo eqüino por meio de tratados técnicos que continham orientações para treinar, alimentar e medicar os cavalos doentes. Em Ugarith (Síria), onde parece ter existido uma escola de equitação com aulas oferecidas em salas sob teto e na cultura Micênica (Grécia antiga), é marcante o reconhecimento ao ofício de domador de cavalos. Finalmente, no famoso livro de Kikkuli, o mais antigo tratado de equitação que se tem notícia, escrito em tábuas de argila no século XIV a.C., ensina-se a arte eqüestre aos Hiti- tas, demonstrando já a existência de especialistas em hipologia. Os exemplos anteriores, apresentados para o caso do cavalo, são tirados da literatura não propriamente ao acaso e assinalam dois aspectos importantes a se destacar quanto ao surgimento dos ofícios e das profissões: por um lado, a presença de grupamentos específicos de pessoas que exerciam um ofício especializado que visava o manejo de animais e, por outro, a existência de manuscritos e aulas ministradas em instituições criadas na época com o objetivo de organizar os conhecimentos empíricos.

\section{Desenvolvimento, ciência e trabalho:um bre- ve olhar sistêmico.}

No discurso de posse dos novos acadêmicos, em 2004, da Academia Brasileira de Ciências, $\mathrm{ABC}$, proferido pelo Acadêmico Eduardo Moacyr Kriege, colheu-se interessante pensamento que resume parte da concepção atual dos objetivos das Ciências, tanto em seu contexto intrinsecamente acadêmico, quanto na órbita do seu papel no desenvolvimento do trabalho e das sociedades humanas:

Até um passado recente, o cidadão podia exercer plenamente os seus direitos e deveres com um mínimo de conhecimento sobre as Ciências. Hoje, ele está imerso em Ciência e Tecnologia e nas suas conseqüências: a expectativa de vida aumenta continuamente, porque temos mais e melhores alimentos, medicamentos e conhecemos, com o advento da genômica, muito melhor: os segredos da vida. Surgem novos empregos e profissões baseadas em conhecimentos recentes e, simultaneamente, muitas profissões são extintas e vários empregos desaparecem simplesmente porque as atividades correspondentes não têm mais importância econômica, estratégica ou social. Por isso, todo cidadão de hoje precisa ter uma educação científica que o capacite, pelo menos, para entender o que se passa ao seu redor. Ele tem de tomar decisões complexas que exigem informação sobre a Ciência, sobre a natureza do conhecimento científico e sobre suas limitações e potencialidades... Nossa preocupação crescente para que o uso do Conhecimento se faça exclusivamente em benefício do homem, promovendo o desenvolvimento sustentável, evitando a degradação do meio-ambiente, asse- 
gurando às gerações futuras melhores condições de vida, contribuindo para diminuir as desigualdades, enfim, a Ciência para a Sociedade é legítima e deve ser incentivada. Isso não exclui, mas, ao contrário, exige que nos dediquemos cada vez mais a promover a Ciência de qualidade, batalhando para que a excelência e o mérito sejam os critérios prevalentes no julgamento das questões científicas e universitárias; enfim, é praticando a boa Ciência e respeitando a ética que mantemos a credibilidade indispensável para influenciar o desenvolvimento científico do país. Ainda é necessário expandir a base científica nas diferentes regiões do país, aumentando o número de institutos e universidades qualificadas cientificamente, aumentar o número e a qualidade dos grupos de pesquisa melhorando as condições de trabalho dos cientistas, contribuir para o desenvolvimento de um eficiente sistema nacional de CT\&I (Ciência, Tecnologia e Inovação), participar ativamente na educação de ciência em todos os níveis e lutar para que a importância estratégica da Ciência seja reconhecida pela nossa Sociedade, como o é nos países desenvolvidos. Esses são alguns dos nossos grandes desafios. Finalmente, não devemos nos esquecer que o Conhecimento sempre foi considerado um patrimônio da humanidade e que a difusão das novas descobertas desconhece fronteiras. Portanto, a Ciência e a comunidade científica podem e devem ser consideradas como importantes elos de aproximação dos povos e instrumentos nobres e efetivos para promover a fraternidade universal. Os riscos de conflitos provocados por choques de civilizações ou credos religiosos poderão ser, em parte, superados quando a Educação e o Conhecimento forem mais eqüitativamente distribuídos entre os povos, permitindo que cada país conte com um mínimo de capacitação científica e tecnológica que lhes assegure de uma forma genuinamente autóctone promover o seu desenvolvimento social e econômico, melhorando a qualidade de vida de sua gente.

É impensável desvincular a idéia de desenvolver Ciência e Educação sem que essas tenham ressonância no mundo do trabalho, atados com fortes elos para o avanço da sociedade. Nin- guém pode ser considerado dono exclusivo do Conhecimento ou das Ciências e muito menos do trabalho. No entanto, há que se esclarecer que existem forças atuantes tanto na mercantilização das ciências como também da educação, sobretudo a educação superior. Assim, embora seja objeto de repúdio pela maioria da comunidade científica e acadêmica, a transformação do conhecimento e da educação em produtos de mercado tem sido proposta pela Organização Mundial do Comércio. Isso tem permitido uma frontal especulação de âmbito mundial nestes setores que deveriam ser entendidos como investimentos que suportam a soberania e independência das nações, bem como a preservação de suas identidades e patrimônios culturais e de saberes científicos (KNIGHT, 2003; MEHTA, 2001).

\section{Arte e ciência:}

\section{O que é zootecnia? Quais são suas fronteiras?}

Revela Estrella Bohadana ${ }^{14}$ que

é como condensação dos desejos humanos que podemos compreender a "ilusão", cuja expressão encontra-se no metafórico diálogo concebido por Voltaire, quando o Filósofo, dirigindo-se à Natureza, afirma: Sendo tão rústica em tuas montanhas, em teus desertos, em teus mares, gostaria de saber como te revelas, no entanto, tão engenhosa em teus animais, em teus vegetais? Complacente, a Natureza responde: "Minha pobre criança, queres que te diga a verdade? É que me foi dado um nome que não me convinha: chamam-me Natureza, mas sou inteiramente Arte. Atribuindo a Natureza como Arte, Voltaire denuncia a impossibilidade de se conhecer em profundidade os mistérios que envolvem $\mathrm{o}$ ato de criar, indicando, ao mesmo tempo, o preciso limite que enfrentará qualquer projeto que tenha como meta tornar a natureza um puro objeto de conhecimento...

As dimensões de Arte e de Ciência interpostas pelo pensamento de Bohadana se resumem nas relações de desejo, limite e possibilidades hu-

14 Estrella Bohadana - Doutora em História dos Sistemas de Pensamento - ECO - Universidade Federal do Rio de Janeiro; Professora do Mestrado em Educação e Cultura Contemporânea da Universidade Estácio de Sá. Autora de vários livros e artigos Transformações: cultura, subjetividade e linguagem. 
manas. As primeiras definições de Zootecnia nos dicionários de língua portuguesa conferiam a esta o atributo de "Arte de criar os animais", nos atuais tratados lingüísticos (ver, por exemplo, em Aurélio Buarque de Holanda, Dicionário Básico) reduziu-se seu significado para "Estudo científico da criação e aperfeiçoamento dos animais domésticos". A Arte em sua abstração e amplitude foi descortinada pela Ciência em uma equivocada aparência de mais status ou pretenso domínio do COnhecimento avançado.

Como já mencionado, a utilização dos animais em benefício do homem e seu processo de domesticação remontam da pré-história e têmse registros em inúmeras pinturas rupestres. A criação de animais, como parte das habilidades fundamentais à sobrevivência humana, é citada no velho testamento e por diversos autores da Antigüidade, entre eles Xenofonte, Plínio, Paladium, Epicarnus, Estrabão, etc. Porém, foi no reinado de Deoclesiano, há aproximadamente 2000 anos, que se instituiu um tratado de organização para a atividade agrícola, no qual se incluíam a agricultura, a criação e a higiene dos animais. Não obstante, o uso de animais para o transporte, a guerra e o trabalho foi vital em quase toda história humana.

Com a invasão Bárbara e a derrocada do império Romano, houve uma redução dos estudos da arte de criar os animais e por essa época a atividade agrícola estava mergulhada no mais absoluto empirismo. Somente após o fim da idade das trevas e a chegada da era renascentista foi possível o ressurgimento e o desenvolvimento de novas idéias relativas às atividades agrárias com o uso racional de animais para o trabalho e a produção de alimentos. O homem passou a vislumbrar a produção organizada de animais domésticos para o trabalho do campo, esporte, lazer, alimentação em escala e como fator econômico integrante das atividades agrícolas.

O ensino formal da produção animal nasceu em 1848, na França, com a criação, pelo Conde de Gasparin, no Instituto Agronômico de Versailles, de uma cadeira destinada ao estudo dos animais domésticos como um corpo independente de doutrinas denominada como Zootechnie, Zootecnia no português, desligando-se do ensino vigente da Agricultura Geral. Os candidatos às cadeiras de professor de Zootecnia deviam expor numa tese os planos de ensino da matéria que desejavam lecionar. Desta forma, em fins de 1849, um jovem naturalista, chamado Émile Baudement, conquistou a aprovação unânime dos membros do júri, pelas suas idéias inovadoras, explicando em sua dissertação que a Zootecnia é uma ciência que explica os acontecimentos para constatar os fatos: "Dire que la Zootechnie est une science c'est exprimer un voeu et un besoin plutôt que constater un fat". Portanto, a Zootecnia deixou de ser somente uma prática que se aprendia com a "lida" com o gado, para ser também uma arte ou ciência aplicada que se apreende observando e experimentando, conforme definiu Cornevin em 1881. A Zootecnia então entendida como ciência complexa deveria evoluir, sendo ensinada nas universidades e centros de altos estudos, tendo estas idéias se dispersado pelo mundo civilizado.

A expressão Zootecnia veio inicialmente a ser adotada somente pelos povos de origem latina e alemã, porquanto os ingleses (nos países de língua Inglesa, o termo foi substituído pela nomenclatura Animal Science) e demais povos europeus e ainda os americanos não a utilizavam, nem reconheciam no Zootecnista francês Baudement o primeiro professor da Arte e Ciência da criação animal. Na linguagem científica do século XIX e na primeira metade do XX, passou-se a empregar com mais intensidade o termo Zootecnia, porém, ainda de maneira marginal, como uma classe a mais dentro de um grupo de atividades e, quase sempre, com um significado incerto. No entanto, como reafirmou Octávio Domingues em seu trabalho "Considerações sobre o ensino da Zootecnia”, em 1944, que na Cyclopedia of American Agriculture, (v. 3, p. 273, de Bailey), deparamos o vocábulo Zootechny para designar "o conhecimento, a prática e as indústrias concernentes à criação dos animais". O termo Zootechny para Zootecnia ou o vocábulo Zootechnician para indicar Zootecnista são facilmente encontrados em dicionários eletrônicos modernos como, por exemplo, no Merriam-Webster On Line Dictionary (bttp:// $w w w \cdot m-w \cdot c o m /)$. A expressão Zootecnia já ultrapassou as fronteiras ocidentais estando igualmente assimilada para o chinês (Taiwan) como Shee Моo Shuey ${ }^{15}$

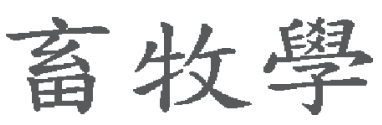

15 Ideograma chinês acessado em <http://www.formosa-translation.com/chinese/z/zzz101.html>. 
Assim surgidas formalmente na Europa como conseqüência ao impulso dado pela Revolução Industrial, as Ciências Agrárias, incluindo a Zootecnia, definiram rapidamente seu objeto de trabalho tanto como Ciências da órbita acadêmica quanto como profissões específicas. Com o surgimento das profissões agrárias, nomeadas de agricultura científica e que, aliás, eram bem diferentes aos ofícios gerados pela agricultura prática, tentava-se articular os desenvolvimentos regidos nas ciências básicas (química, biologia, botânica, zoologia e genética) à solução dos problemas práticos próprios das atividades agropecuárias. Alguns autores têm sugerido que a consolidação das Ciências Agrárias e de suas profissões associadas, além das novas práticas agrícolas que surgiram a partir de seu desenvolvimento, foi possível porque a sociedade européia estava procurando mudanças nas técnicas agropecuárias.

A Zootecnia se insere lúdica e pretensiosamente como Arte, confundindo-se no imaginário humano de melhor compreender e intervir na Natureza, embora a leitura cartesiana contemporânea a enquadre como Ciência. Não obstante, sem demérito, pretende mais a Zootecnia, e isso já se revelou na sua própria evolução de significado, que como Ciência dedicada ao estudo da criação dos animais, tendo em vista a sua produção de bens e serviços para a Sociedade, incluindo a industrialização desses, atinge mais que aqueles animais circunscritos como domésticos, permeia os animais úteis ao homem, inscrevendo-se além dos animais de produção ou de interesse econômico aos de preservação ou conservação. Pois, definida como Ciência, estuda e revela os acontecimentos dos animais sem limites, em função do bem-estar do homem.

Outro importante aspecto foi considerado na definição de Zootecnia elaborada por Octávio Domingues, em 1929, que assume ainda uma alta relevância no desenvolvimento desta área de conhecimentos nas regiões tropicais do planeta: a adaptação dos animais ao clima. Disse o Patrono da Zootecnia brasileira: “... Para o Zootecnista brasileiro, ela não é apenas "a ciência da produção e da exploração das máquinas vivas”, como a definiu Sanson. Porque para realizar essa tarefa, nas regiões como o Brasil, a adaptação vai ser o trabalho primordial e básico, anterior a todos os outros. Daí impor-se uma nova definição para a Zootecnia dos trópicos, e que podemos enunciar nos seguintes termos: "É a ciência aplicada que estuda e aperfeiçoa os meios de promover a adaptação econômica do animal ao ambiente criatório, e deste àquele".

1. Considerando a evolução e dinâmica inerente a cada área do conhecimento, a Zootecnia experimentou ao longo dos anos uma readequação de identidade que se revela no ensino de graduação em Zootecnia ofertado no Brasil, como pode ser constatado na "Sinopse Estatística dos Cursos de Graduação em Zootecnia", publicada em 2002, pela Comissão Nacional de Ensino da Zootecnia do Conselho Federal de Medicina Veterinária. Também se ressaltam as recentes Diretrizes Curriculares para os Cursos de Graduação em Zootecnia, aprovadas pelo Conselho Nacional de Educação em sua reunião ordinária dos dias 9, 10 e 11 de novembro de 2004 pelo parecer CES 337/04 (súmulas publicadas no D.O.U. de 29 de dezembro de 2004, seção 1, página 269), homologado pelo então Sr. Ministro da Educação, Dr. Tarso Genro, em 17 de dezembro de 2004 (D.O.U. de 20 de dezembro de 2004, número 243, seção 1, página 29) e definidas na Resolução número 4 de 02 de fevereiro de 2006, publicadas no D.O.U. número 25, de 03 de fevereiro de 2006, seção 1, páginas 34 e 35 (texto completo no anexo I e análise detalhada apresentada no último capítulo deste documento).

As premissas históricas e de ação profissional anteriormente discorrida já estão inseridas no contexto regulamentar e de avaliação vigentes dos cursos superiores de Zootecnia e partiram tanto da evolução própria da Zootecnia como Ciência e Profissão como do pressuposto legal conferido pela Lei 5.550 de 04 de dezembro de 1968, que institui e regulamenta a profissão de Zootecnista rezando em seu artigo Art. $3^{\circ}$ que são privativas dos profissionais mencionados no art. $2^{\circ}$ desta Lei as seguintes atividades:

a) Planejar, dirigir e realizar pesquisas que visem a informar e a orientar a criação dos animais domésticos em todos os seus ramos e aspectos. 
b) Promover e aplicar medidas de fomento à produção dos mesmos instituindo ou adotando os processos e regimes, genéticos e alimentares, que se revelarem mais indicados ao aprimoramento das diversas espécies e raças, inclusive com o condicionamento de sua melhor adaptação ao meio ambiente, com vistas aos objetivos de sua criação e ao destino dos seus produtos.

c) Exercer a supervisão técnica das exposições oficiais e a que eles concorrem, bem como a das estações experimentais destinadas à sua criação.

d) Participar dos exames a que os mesmos hajam de ser submetidos, para o efeito de sua inscrição nas Sociedades de Registro Genealógico.

É inegável que as ações previstas em Lei são suficientemente abrangentes na conformação dos desdobramentos nas habilidades e competências apresentadas anteriormente. Quando no inciso "a" atribui-se que o Zootecnista planeja, dirige e realiza pesquisas visando a orientação da criação animal em todos os seus ramos e aspectos, é lúcido perceber que o legislador definiu os objetivos da Zootecnia como ciência, dando o devido valor ao seu caráter investigativo e a conseqüente aplicação das técnicas na orientação da criação animal. Não deve haver reducionismo quando a leitura desatenta do arcabouço legal implica erroneamente interpretar que a ação de pesquisa restringe o papel profissional do Zootecnista, muito ao contrário, amplia e confere a devida complexidade, sofisticando sua atribuição no devido campo interpretativo da natureza e na manipulação dessas informações para o bem-comum do homem.

Da mesma forma "promover e aplicar medidas de fomento à produção... com vistas ao objetivo da criação e ao destino de seus produtos", previsto no inciso "b" da citada Lei, confere ao Zootecnista uma atribuição central de gerador de desenvolvimento, de inovação e aplicação de tecnologias na produção animal, ressaltando na definição o significado de Zootecnia exercida nos trópicos proposto por Octávio Domingues, quando são colocados em relevo o aprimoramento, o acondicionamento e o processo de adaptação das diversas espécies e raças (aqui também ultrapassando a ação do Zootecnista além do animal domés- tico!). Igualmente importante estão em destaque no texto legal as ações profissionais relativas ao destino dos produtos dos animais, que resultam especialmente no campo dos saberes das tecnologias dos produtos de origem animal.

O significado literal de fomentar se refere estritamente a "promover o desenvolvimento, o progresso, estímulo, facilitação". "Facilitar é a ação pela qual se removem os obstáculos ou dificuldades". Assim posto, implica na função de fomentador da produção animal a solução de problemas e a superação de entraves na área em questão, tendo em vista, mais uma vez, o bem-estar social.

Os incisos "c" e "d" do artigo que refere às atribuições do Zootecnista conferem contornos muito especiais na ação profissional. O exercício de supervisão técnica de exposições de animais, bem como de estações experimentais, e ainda a participação nos exames necessários nos animais de criação para efeito de inscrição em Sociedades de Registro Genealógico mostra que a participação dos Zootecnistas é insubstituível e fundamental na avaliação e na apresentação pública de animais que se constituam em situações de interesse econômico. Isso credita em sua intervenção técnica um olhar privilegiado que deve estar presente, irremediavelmente, em qualquer hipótese em que se constitua a necessidade de habilitação ou exclusão de animais para sua permanência no âmbito do sistema produtivo, em exposições, leilões, etc... Nesse sentido, a Lei concede ao Zootecnista o poder de chancela sobre o material genético de animais, tendo em vista os riscos ou vantagens de sua perpetuação nos rebanhos. O Zootecnista, ao exercer a ação profissional de instrução técnica da qualidade dos animais, deve participar de forma preponderante seu papel para o êxito dos processos e regimes de melhoria da produção animal. A interpretação do texto legal em epígrafe, considerando as situações práticas nas quais o Zootecnista interpõe seu parecer, não deixa dúvidas e se desdobra obrigatoriamente na elaboração de exames, laudos e perícias em animais que com esta participação profissional se garante aferição técnica qualificada para todos os fins, inclusive para uso judicial.

A leitura cuidadosa da Lei 5.550/68 mostra que a Zootecnia, conformada, sobretudo, em sua responsabilidade social, no tocante à sua relevância como ciência e profissão, não possui fronteiras facilmente identificáveis, tendo em vista sua vasta acepção e significado. 


\section{Habilidades e competências: onde o discurso curricular se torna efetivo?}

Nas definições clássicas, temos que: Competência - é a articulação de conhecimentos, percepção, pensamento, emoção, vontade, memória, linguagem, motricidade, atenção, consciência, valores, juízo, mobilizados em busca de uma solução, enfim, poderíamos usar a expressão "gestão mental" para caracterizar competência. Habilidades - são processos mentais desenvolvidos e a desenvolver. São necessárias para realizar aprendizagens e continuar aprendendo por toda a vida. Algumas delas: criar, decidir, planejar, ler, interpretar, hipotetizar, descrever, memorizar, deduzir, analisar, dramatizar, sintetizar, aplicar, escrever, elaborar, contar, decidir.

Idalberto Chiavenato ${ }^{16}$, em seu artigo " $O$ triângulo da excelência”, em uma visão muito própria da gestão de pessoas para os interesses das empresas privadas, procura explicitar que o conhecimento está se tornando a principal riqueza da Era da Informação. Tece assim as seguintes afirmativas: é graças ao conhecimento que as pessoas podem transformar os problemas em soluções, os desafios em oportunidades, as idéias em produtos e os objetivos em realidade... Investir no conhecimento significa investir no seu próprio capital intelectual para alcançar retornos significativos na vida profissional... O importante é enriquecer as habilidades de que dispomos com o conhecimento agregado em sala. Algumas profissões exigem algo mais do que apenas conhecimentos e habilidades para o seu exercício. Elas exigem também competências. E o que são competências? Competência significa a capacidade de fazer as coisas acontecerem, de alcançar metas e objetivos. No fundo, competência significa transformar conhecimentos e habilidades em realizações pessoais ou empresariais. Isso exige postura pessoal, atitude empreendedora, assumir riscos, visão de futuro, espírito de luta, senso de realização, discernimento, coragem, perseverança. O triângulo da excelência envolve conhecimentos, habilidades e competências e precisa ser seriamente levado em conta por quem pretende ser bem-sucedido profissionalmente. Mas qual é o mais importante desses três impulsionadores da excelência profissional? Em qual deles centrar os maiores esforços? Na verdade, todos eles são importantes. Mas decididamente o conjunto dos sinais que costumamos descrever como competências sai disparado na frente dos demais. Pela simples razão de que tanto a aplicação do conhecimento como a obtenção dos resultados por meio do conhecimento e das habilidades depende da competência pessoal.

Em um ângulo mais filosófico do significado de competência, Garcia (2005) coloca que não existe uma noção clara e partilhada das competências. Mais do que definir convém conceituar por diferentes ângulos. Poderíamos dizer que uma competência permite mobilizar conhecimentos a fim de se enfrentar uma determinada situação. Destacamos aqui o termo mobilizar. A competência não é o uso estático de regrinhas aprendidas, mas uma capacidade de lançar mão dos mais variados recursos, de forma criativa e inovadora, no momento e do modo necessário. A competência abarca, portanto, um conjunto de coisas. Perrenoud fala de esquemas, em um sentido muito próprio. Seguindo a concepção Piagetiana, o esquema é uma estrutura invariante de uma operação ou de uma ação... Diz Perrenoud que "uma competência orquestra um conjunto de esquemas. Envolve diversos esquemas de percepção, pensamento, avaliação e ação... O conceito de habilidade também varia de autor para autor. Em geral, as habilidades são consideradas como algo menos amplo do que as competências. Assim, a competência estaria constituída por várias habilidades. Entretanto, uma habilidade não "pertence" a determinada competência, uma vez que uma mesma habilidade pode contribuir para competências diferentes. Uma pessoa, por exemplo, que tenha uma boa expressão verbal (considerando que isso seja uma habilidade), pode se utilizar dela para ser um bom professor, um radialista, um advogado, ou mesmo um demagogo. Em cada caso, essa habilidade estará compondo competências diferentes.

Pacheco (2003), analisando as políticas curriculares da atualidade, argumenta que a "pedagogia por competências" é, numa perspectiva de ressignificação da linguagem educativa e das práticas curriculares, o prolongamento da "pedagogia por objetivos”. Diz-nos o Dicionário da Língua Portuguesa Contemporânea que competência

16 Idalberto Chiavenato é colunista do <empregos.com.br>, filósofo, pedagogo, mestre (MBA) e doutor (Ph.D.) em Administração de Empresas e consultor de empresas. 
significa "capacidade, poder de apreciar ou resolver dado assunto", "conjunto de conhecimentos teóricos ou práticos que uma pessoa domina, de requisitos que preenche e são necessários para um dado fim", "aptidão para fazer bem alguma coisa" e objetivo quer dizer "resultado que se pretende alcançar", "ponto de convergência", propósito". O que existe em comum nestes dois temos? Competência indica o que é necessário para percorrer um dado caminho e objetivo precisa o resultado que deve ser alcançado no final desse mesmo caminho.

Para Gagné (1976), os campos da aprendizagem, que são o denominador comum do objetivo e da competência, incluem a informação verbal, as habilidades intelectuais, as estratégias cognitivas, as atitudes e as habilidades motoras. Tais campos correspondem a possibilidades de construção dos espaços culturais escolares por meio do currículo. O âmbito do conhecimento escolar tem sido questionado na base de uma teoria aristotélica do habitus, ou seja, no reconhecimento de uma teoria de aprendizagem orientada para a prática, pressupondo quer a disposição e hábito de escolha preferencial quer a escolha deliberada (PACHECO, 1999): O habitus, tal como o define Bourdieu (1997), "é essa espécie de sentido prático do que se deve fazer numa situação dada”. E é precisamente o sentido de ação que está na base não só da institucionalização do currículo a partir do século XIX, na medida em que a escola se torna numa instituição de transmissão do conhecimento com fins sociais muito bem demarcados, mas também da validade kantiana do conhecimento por meio dos pressupostos da objetividade e da universalidade... Na "pedagogia por objetivos", objeto, operação cognitiva e produto são os três elementos básicos que explicam a estrutura lógica da aprendizagem dos alunos. E na "pedagogia por competências"? Ao definir competência como "saber mobilizar", Le Boterf (1997) acentua a complexidade do saber-fazer, na base de um dado conteúdo ou objeto, que passa pela existência de operações cognitivas complexas com vistas a obter determinados resultados. Objetivo e competência, para além de divergências, têm em comum a incorporação e aplicação de um saber que é prático porque é contextualizado a situações de resolução de problemas. Quer dizer então que o saberfazer cognitivo do aprendiz está dependente do contexto que lhe exige o babitus de agir em fun- ção dos problemas e situações a que se reporta. A mesma situação se verifica no mundo do trabalho, não sendo de estranhar que tenha sido a lógica empresarial, ligada à qualidade, ao desempenho e à mobilização de recursos, a trazer para o interior da escola a noção de competência...

\section{Abrangência profissional do Zootecnista}

Como enfatizado anteriormente, os Zootecnistas dos dias atuais devem ser profissionais com sólida base de conhecimentos científicos dotado de consciência ética, política, com visão crítica e global da conjuntura econômica, social, política e cultural da região onde atua, do Brasil e do Mundo.

Para atender ao perfil desejado do Zootecnista, reforça-se a necessidade de uma formação científica pautada em conbecimentos essenciais para o entendimento das diversas áreas de atuação deste profissional, considerada a dinâmica das transformações sociais, econômicas e ambientais. Nesse sentido, faz-se importante pensar em cursos de formação profissional que contemplem abordagem das disciplinas e conteúdos programáticos diferentes do contexto clássico segmentado. Que sejam centrados na produção das diferentes espécies animais, passando agora para uma valorização de grandes áreas do conhecimento zootécnico, com maior igualdade de pesos entre estas, integrando os conbecimentos básicos, de formação geral e os profissionalizantes, permitindo ao acadêmico vivenciar os conteúdos programáticos de forma integrada, estimulando o desenvolvimento e aperfeiçoamento de habilidades e competências individuais.

A vivência acadêmica não pode estar restrita ao universo das disciplinas ministradas. A participação dos discentes nas pesquisas desenvolvidas pelos docentes e pós-graduandos das diferentes Instituições de Ensino Superior (IES) é necessária, assim como nas atividades culturais e de extensão promovidas. Todavia, inúmeras vezes, a carga horária elevada das disciplinas impedem ou colocam em segundo plano estas atividades.

A flexibilização dos currículos e a redução da carga horária formal, abrindo "janelas" para o estabelecimento de formações complementares e livres, é uma modificação profunda na es- 
trutura atual dos cursos e demanda um esforço de adaptação das IES, dos seus docentes e também dos discentes, o que seria uma utopia imaginar possível em um curto espaço temporal.

Os campos de atuações desejados apontam para um universo peculiar de cada IES e de cada região, todavia algumas destas são pretendidas:

1. Cadeia Agroindustrial de Carnes.

2. Cadeia Agroindustrial do Leite.

3. Cadeia Agroindustrial de Aves.

4. Cadeia Agroindustrial de Fibras Animais, Rações para animais e de outros produtos de interesse Zootécnico.

5. Cadeia Negocial de Criação Animal para lazer e companhia.

6. Planejamento, Consultoria e Assistência Agropecuária.

7. Gestão Empresarial e Marketing.

8. Gestão Ambiental e Sustentável do Agronegócio.

9. Desenvolvimento e Política Agrícola.

10. Docência, Pesquisa e Extensão.

Em todo o mundo, desde sua consolidação como profissão de nível superior e ciência aplicada, a Zootecnia tem confirmado um papel preponderante e estratégico nas diferentes Sociedades modernas, conquistando um perfil profissional ligado à produção e produtividade animal, como pode ser apreciado a partir de suas habilidades e competências na atualidade.

Esta identificação da área de atuação profissional que se encontra em franca expansão e sedimentação deve ser melhorada cada vez mais com o esforço conjunto das instituições de ensino e da Sociedade, que deve exigir irrestrita qualidade dos serviços nesta seara. O exercício com qualidade das habilidades e competências que se espera para o Zootecnista o transformará, em curto prazo, em um profissional estratégico para o desenvolvimento nacional. Sem retórica ou demagogia, o esforço e parceria também esperados das demais profissões de nível superior que se conformam nas ciências agrárias ou ciências afins devem concorrer ao mesmo propósito. Para tanto, os desafios que se apresentam nos dias de hoje, que impedem o desenvolvimento real do Brasil, podem ser superados com uma substancial participação das Ciências Agrárias, em destaque a Zootecnia.

\section{O ensino da Zootecnia}

\section{Marcos bistóricos}

Em nossa perspectiva sul americana, a Universidade Brasileira é uma figura institucional recente. A criação formal da primeira Universidade no Brasil só ocorreu em 1920 no Rio de Janeiro (existiam cursos superiores, mas não universidades), assim mesmo, tendo sofrido muita influência de modelos exógenos. Um dos motivos desse processo tardio foi a proibição estabelecida pela monarquia portuguesa até a chegada da Família Imperial no País em 1808. A presença da Corte no Rio de Janeiro, com D. João VI, exigia a instituição do então denominado Ensino Superior. O sistema norte-americano dos Land Grant Collegessluenciou sobremaneira o formato de algumas instituições originalmente dedicadas às Ciências Agrárias no Brasil, em especial a partir dos anos 20, no século passado, como as atuais Universidades Federais de Viçosa e de Lavras em Minas Gerais, bem como a Universidade Federal Rural do Rio de Janeiro, antiga Escola Nacional de Agronomia e a de Veterinária.

O Professor Guy Capdeville (1991), em seu laborioso livro "O Ensino Superior Agrícola no Brasil", revela-nos que a historiografia brasileira referente à agricultura é muito incipiente. Ao inventariar os documentos históricos referentes ao surgimento dos processos agrícolas racionalizados e ao surgimento das profissões responsáveis pelo desenvolvimento da agropecuária no Brasil, identifica inicialmente D. João, O Príncipe Regente, que argüia que "aprendia-se a profissão agrícola somente pela simples rotina" e atribuía a esse fato os insucessos dos empreendimentos agrícolas. D. João, durante sua Regência e Reinado, propôs os primeiros cursos agrícolas a partir da também criação dos Hortos Imperiais, mais tarde denominados como "Jardins Botânicos" (Carta Régia de 25 de junho de 1812). Posteriormente, no Primeiro e Segundo Impérios, estabeleceram-se inúmeras instituições agrícolas, culminando com a formação de profissionais dedicados a seara agrária ainda sob regime imperial.

Segundo a análise do Professor Capdeville, a agricultura colonial dos séculos XVI, XVII e XVIII, com seus restos feudais, o latifúndio e o escravismo impediram o surgimento do campesinato e atrasaram a difusão de trabalho assalariado 
na agricultura. Em pleno século XIX, a economia agrária brasileira assentava-se sobre o trabalho escravo e o regime de grandes propriedades de latifúndio agrário e pecuário. Praticava-se a monocultura de produtos tropicais, voltada para a exportação. A agricultura de subsistência merecia atenção somente nos momentos de crise. Havia regiões onde os grandes proprietários monocultores proibiam as lavouras de subsistência em suas terras, agravando o problema do abastecimento e reforçando a dependência de seus servos e agregados.

Formalmente, os primeiros cursos superiores nas Ciências Agrárias no Brasil nasceram na Bahia em 1877, mas somente foram regulamentados em 1910 (Escola Agrícola de São Bento das Lages). Até o início do século XX, distinguiam-se quatro profissões reconhecidas como de nível superior: Silvicultores, Veterinários, Engenheiros Agrícolas e Agrônomos.

A Zootecnia como profissão de nível superior veio a surgir no Brasil a partir do estímulo e iniciativa de um seleto grupo de Agrônomos e Veterinários com perspectiva de visão do futuro. Reunidos na sessão solene de encerramento da II Reunião Anual da Sociedade Brasileira de Zootecnia em Porto Alegre, no dia 24 de setembro de 1952, no restaurante Rener, registraram as seguintes palavras: (livro de atas $\mathrm{n}^{\circ} \mathrm{I}$ SBZ - página 19, verso) - "Usou a palavra o Dr. Manoel Soares que teve a oportunidade de manifestar a sua opinião a respeito da necessidade de ser criada a carreira e a profissão de Zootecnista. Falaram ainda corroborando no mesmo ponto de vista os Profs. Waldemar Raythe e Octávio Domingues e Dr. Glacy Pinheiro Machado". Na mesma sessão, o Dr. Geraldo Veloso Nunes Vieira propõe uma moção apresentada em plenário onde consta a necessidade de uma reunião de professores de Zootecnia do País, de escolas de Agronomia e Veterinária, para debater um currículo mínimo de um curso independente de Zootecnia. Tendo sido aprovada a moção de uma Reunião Nacional de Professores de Zootecnia que de fato veio a ocorrer no dia 28 de julho de 1953, no Pavilhão de Zootecnia da atual Universidade Federal Rural do Rio de Janeiro (km 47 - Ex-Universidade Rural do Brasil), sob os auspícios da Sociedade Brasileira de Zootecnia que reuniu 16 professores catedráticos de Zootecnia, representando 10 Universidades renomadas do Brasil. Sob a presidência do Professor Octávio Domingues, uma comissão foi constituída pelos seguintes professores: Alcides di Piravicini Torres, Waldemar Raythe, Luiz Rodrigues Fontes, Joaquim Moreira de Mello, Gomes Pereira, Newton Guimarães Alves e Ernesto Váter Faria, a qual, após dois dias de debates em plenário, aprovou o primeiro currículo de Zootecnia, constando de 56 disciplinas obrigatórias e seis disciplinas eletivas, a serem cursadas em quatro anos, o qual veio a servir de orientação para a criação dos primeiros cursos de Zootecnia. Posteriormente, houve resistência ao encaminhamento do estudo realizado para o seu endosso em plenário na III Reunião Anual da Sociedade Brasileira de Zootecnia de Salvador-BA, em 1953, entendido este fato como um protesto corporativo de Veterinários e Agrônomos que possuíam uma percepção mais retrógrada e exclusivista para suas profissões quanto ao exercício da Zootecnia como atividade profissional. O emérito Professor de origem acreana, Dr. Octávio Domingues, ameaçou abandonar a presidência da SBZ caso não se consubstanciasse a discussão da proposta, que após debates fervorosos, aprovou-se por unanimidade na assembléia de encerramento a seguinte moção: "Considerando as falhas que se vem observando no currículo das escolas de Agronomia e de Veterinária, na preparação de Zootecnistas em nosso país, sugerimos que, ouvido o plenário, seja recomendado à SBZ que apóie o movimento no sentido da criação de escolas de Zootecnia, a fim de que possam as mesmas formar profissionais devidamente preparados para a especialidade".

Em 1966, não menos com muita luta e perseverança e decisiva participação de Octávio Domingues, que peregrinou em todo País em busca da edificação de seu projeto de instalação de um curso superior independente de Zootecnia, criou-se em Uruguaiana-RS, na Pontifícia Universidade Católica do Rio Grande do Sul, o primeiro curso superior de Zootecnia no Brasil, que teve sua aula inaugural dia 13 de maio, hoje comemorado como o "Dia do Zootecnista". A profissão de Zootecnista foi regulamentada dois anos depois pela Lei 5550/68 de 04 de dezembro de 1968. E por uma deformação mediada pelos interesses corporativos e políticos é a única Lei que permite a co-participação multiprofissional de Zootecnistas com Engenheiros Agrônomos e Médicos Veterinários em uma mesma atuação na área do conhecimento (evidenciada na sua alínea "c"), sem que as demais profissões tenham todo o treina- 
mento para as habilidades e competências específicas desejáveis para o perfil do exercício da Zootecnia devidamente ampliado em estudos no ensino de graduação.

A Reunião Técnica Internacional de professores de Zootecnia, ocorrida de 8 a 11 de setembro de 1971, em Belo Horizonte, sob o patrocínio do Instituto Interamericano de Ciências Agrárias (IICA) da Organização dos Estados Americanos (OEA), reconheceu a necessidade de se criar mais cursos superiores de Zootecnia, paralelamente aos de Agronomia e de Veterinária, corroborando com as moções anteriores da Sociedade Brasileira de Zootecnia.

Octávio Domingues faleceu em 1972, tendo sido testemunha ativa da criação de outros cinco cursos de Zootecnia no Brasil. Em sua memória e em reconhecimento à participação decisiva no estabelecimento do ensino superior de Zootecnia no Brasil, Octávio Domingues é lembrado como o Patrono da Zootecnia Brasileira.

\section{Perfil do ensino da Zootecnia}

A partir do resgate dos fatos que mais marcaram nossa história profissional, é importante conhecermos de forma panorâmica a situação atual do ensino de Zootecnia no País, para que possamos fazer uma análise de prospecção que caracterize a posição da Zootecnia frente aos aspectos mais relevantes do ensino superior brasileiro. $\mathrm{O}$ contexto apresentado procura discutir sistematicamente os dados obtidos em estudos da Comissão Nacional de Ensino de Zootecnia do Conselho Federal de Medicina Veterinária (CNEZ gestão 2001-2003) e do Instituto Nacional de Estudos e Projetos do MEC (INEP) e de informações mais atualizadas sobre esta temática.

Em 1992, havia 21 cursos de Zootecnia em atividade. No final de 2005, o país contava com 71 autorizações de cursos (veja tabela a seguir), o que representou um aumento de 238,1\% em um período de apenas treze anos. Registra-se que existem no rol dos atuais cursos dois deles na modalidade de cursos superiores tecnológicos de Zootecnia oferecidos pelos CEFET de Cuiabá, MT e Bambuí, MG. Comparando-se os dados da última década, considerando a dependência administrativa das Instituições de Ensino Superior (IES), em 1992, 60\% dos cursos eram públicos e
$40 \%$ privados. Em 2005, esses valores pouco se alteraram com a maior parte dos cursos em IES públicas (62\%). O INEP (2004) apontou para a proporção de 66\% para os cursos de Zootecnia em IES públicas e de 58,4\% para toda a área de ciências agrárias.

A distribuição dos cursos de Zootecnia por região em 2005 identifica que o maior número encontra-se na região Sudeste, com 25 cursos em atividade. Na região Norte, os cursos de Zootecnia somente foram criados a partir do ano 2000, existindo já sete cursos ativos, sendo que há uma autorização ainda não implementada pela Escola Superior Batista do Amazonas (ESBAM) e a consideração que a Universidade Federal Rural da Amazônia (UFRA) mantém um curso mais antigo em Belém e outro recente fora de sede, em Parauapebas-PA, não relacionado como registrado pelo Ministério da Educação. Neste mesmo contexto, a Universidade Federal Rural de Pernambuco (UFRPE) também oferece um curso fora de sede, em Garanhuns-PE, todavia não relacionado na página de internet da Secretaria de Ensino Superior do (SESu) do Ministério da Educação. A Universidade Estadual Paulista Júlio de Mesquita (UNESP) é a que mantém maior número de cursos em diferentes regiões de São Paulo, sendo os quatro localizados nas cidades de Botucatu, Jaboticabal, Dracena e Ilha Solteira. Nas regiões Norte e Nordeste, com um total de 22 cursos ativos, apenas cinco são privados. O maior incremento de cursos ocorreu na região centro-oeste, que em 1992 possuía dois cursos (Rio Verde-GO e Goiânia-GO) e atualmente conta com 13 IES que mantêm cursos de Zootecnia (sendo um superior tecnológico em Zootecnia) distribuídos em todos os estados da região.

O ensino superior nas IES brasileiras tem experimentado, nos últimos anos, denotada ampliação de alguns de seus parâmetros numéricos como resultado das políticas governamentais. Concorre-se em alcançar a meta de três milhões de matrículas anuais desde 2004, o que paralelamente incluiria na educação superior aproximadamente $30 \%$ dos jovens de 18 a 24 anos (INEP, 2000).

O Censo da Educação Superior no Brasil do ano 2000, publicado pelo Instituto Nacional de Estudos e Pesquisas Educacionais do Ministério da Educação (INEP, 2001), indicou 2.694.245 de matrículas distribuídas em 10.585 cursos de graduação em 1.180 instituições de ensino superior. Isso representou em relação aos dados de 1999 um cres- 
cimento geral de 7,6\% no número de IES, 19,2\% no número de cursos de graduação presenciais e de 13,7\% no total de matrículas. No censo de 2003 (INEP, 2004), o número de IES já se somava em 2.013, que ofertavam 18.644 cursos, mas o número de matrículas se posicionou em 2.320.421, decréscimo provavelmente causado pela escassez de vagas públicas e cada vez um crescente número das vagas em IES privadas que correspondiam em 2003 o percentual de $86,7 \%$ do total.

Os dados publicados em 2001 mostravam também maior crescimento das matrículas nos cursos ofertados no interior $(16,1 \%)$ que nas capitais (11\%). No censo publicado em 2004, as IES inseridas nas cidades interioranas representavam $64,2 \%$ do total, no entanto, 88,9\% delas eram de vínculo administrativo privado. Revela-se ainda nas tendências observadas em INEP (2001) que os alunos estavam ingressando mais jovens no ensino superior, sendo $63,9 \%$ das matrículas referentes à faixa etária de até 24 anos. Outros parâmetros da educação superior daquele censo estão comprovando que a participação feminina no aumento das matrículas passou a ser superior à masculina $(56,24 \%$ do total de matrículas), tendo a matrícula feminina aumentada em 14,9\% desde 1999 até 2001 contra $12,1 \%$ de crescimento das matrículas masculinas. Curiosamente, o número de docentes do sexo feminino em IES aferido em 2003 (INEP, 2004) representava $43,8 \%$ do efetivo de 279.058 professores e este número parece acompanhar o crescimento das matrículas de mulheres no ensino superior.

É sintomático que os números gerais do censo publicado em 2004 também indiquem que as matrículas em IES privadas somem $77,9 \%$ do total e concorram com $66,4 \%$ dos cursos, $86,7 \%$ das vagas em oferta e $67,7 \%$ dos concluintes. Nos grandes números regionais, apenas no nordeste do Brasil a participação de instituições federais de ensino superior (IFES) é mais evidente nas matrículas, destacando-se em cursos noturnos.

Inclui-se, nesta análise, que mesmo tendo sido melhorada a relação percentual entre concluintes/ingressantes na última década, com o valor saltando de 60,8\% em 1990 para 64,9\% em 1998, há um número expressivo de vagas que não são preenchidas. Foi revelado no censo 2000 que das 1.216.287 vagas ofertadas nas IES brasileiras, somente 897.557 vagas foram devidamente ocupadas com a efetivação da matrícula (relação vaga/ ingresso de 1,4: 1). No censo publicado em 2004, a oferta de 2.320.421 vagas teve preenchimento de 1.303 .110 ingressos, o que significa 1,78 vagas/ ingresso.

Não é difícil perceber que provavelmente se está autorizando a abertura de cursos com mais vagas que o perfil e potencial profissiográfico das regiões, ou mais uma vez, nos indicando a extensa incapacidade financeira do cidadão brasileiro em arcar com os altos custos do estudo superior em cursos privados. Não é por mera casualidade que a relação candidato/vaga nos exames de acesso das IES públicas esteja na ordem de 7,9: $1 \mathrm{e}$ em IES privadas a relação esteja em 1,3: 1 (INEP, 2004). Não obstante, deve-se ressaltar a existência de muitos cursos privados com qualidade extensamente assegurada da mesma forma como se encontram alguns cursos em IES públicas em condições de oferta muito precária.

Os índices nacionais mostram que houve uma razoável melhoria na qualificação do corpo docente de todas as IES, sendo $52,1 \%$ a percentagem de mestres e doutores do total do corpo docente em 2000 e 56,3\% em 2003. O índice de qualificação do corpo docente (O IQCD pode variar de 100-mínimo a 500-máximo, na dependência da proporção de titulação dos quadros docentes dedicados aos cursos) está na ordem aproximada de 260 pontos, sendo que os valores das IES privadas são pouco mais baixos que os das IES públicas.

Outro indicador importante se refere ao regime de trabalho do corpo docente. Registra-se que a média nacional das IES privadas mostrava que apenas 16,5\% do corpo docente possuem tempo integral ou dedicação exclusiva em 2000, enquanto nas IES públicas alcança-se um valor de $75,7 \%$. Em 2003, as IES privadas contavam com $14,3 \%$ de seu efetivo docente em tempo integral e $62,2 \%$ na condição de horistas. Nas IES públicas, os contratos em tempo integral representavam neste censo $73 \%$ do efetivo total docente.

\section{Relevância da Zootecnia para o desenvolvimento}

Os animais sempre estiveram ligados à riqueza, ao poder e ao desenvolvimento. A história do Brasil está ligada à saga dos animais. A conquista do território nacional e os avanços eco- 
nômicos e sociais da nossa nação estiveram e estão ligados à Zootecnia. Os ciclos do couro, da canade-açúcar, do ouro, da borracha, as charqueadas do Rio Grande do Sul, a conquista do centrooeste e a colonização de interior do país são exemplos de intensa atividade Zootécnica. Tudo era puxado no lombo dos animais. Suínos, bovinos, aves, ovinos, caprinos, peixes, abelhas, entre outros, sempre constituíram importantes fontes de provimentos.

Desde a implantação do primeiro núcleo de colonização no Brasil, a atividade pecuária não parou de crescer, e hoje ela ocupa posição de destaque no PIB nacional. Contudo, deve-se ressaltar que somente a presença desse importante componente da economia nacional por si só não é suficiente para garantir a tão almejada posição de grande produtor mundial de produtos e subprodutos de origem animal. E necessário também profissionais com sólidos conhecimentos nas práticas de criação e manejo dos animais, na gestão e administração do negócio, com uma visão holística de toda a cadeia produtiva, que possam proporcionar o crescimento de uma produção animal autosustentável e ao mesmo tempo garantir posições já conquistadas.

Sob a ótica da sua função social, a produção animal no Brasil pode complementar a alimentação familiar, aproveitar excedentes e subprodutos da agricultura e da agroindústria, transformando-os em proteínas de alto valor biológico, utilizar efetivamente a mão-de-obra familiar em pequenas propriedades e beneficiar a exploração integrada nos mais diversos sistemas produtivos (SILVA, 1997).

Este fato aponta na direção da necessidade de uma massa crítica de Zootecnistas aptos a atuarem firmemente na pesquisa científica, no desenvolvimento de novas tecnologias de produção, de nutrição, de manejo, na industrialização, na comercialização, na administração, na gestão do agronegócio, enfim, em todos os campos em que se fizer necessária a sua ação profissional, sem, no entanto, deixar de lado o foco sobre o necessário e premente desenvolvimento social do país, buscando-se a produtividade e a competitividade dos sistemas de produção agrícola. Para tanto, tem-se presenciado aumento crescente no número de escolas de Zootecnia, objetivando atender à demanda deste profissional pelo mercado.
As condições edáficas, climáticas e topográficas do território nacional, aliadas às grandes extensões de terra, condição necessária para produção em escala, e às tecnologias de produção, conferem ao nosso país condição ímpar para se consolidar como maior produtor mundial de proteína animal.

Se há alguns anos o enfoque da pecuária nacional se restringia a algumas poucas espécies de animais, atualmente o que se verifica é o aumento da competitividade de um elevado número de cadeias produtivas, o que tem demandado conhecimentos tecnológicos cada vez mais aprofundados por parte dos Zootecnistas, verdadeiros agentes de transformação do seu tempo, agindo, influenciando, provocando mudanças, sempre procurando maior eficiência produtiva, preservando valores culturais e ambientais, buscando qualidade no produto final, com justiça social.

\section{Organização dos Zootecnistas no Brasil}

Um dos marcos na história da Zootecnia brasileira é sem dúvida nenhuma a criação da Associação Brasileira de Zootecnistas, a ABZ. Não seria possível descrever as conquistas e as lutas da órbita profissional, e mesmo a agenda política que conforma os embates contemporâneos, sem deixar de mencionar o papel que a ABZ representa para os Zootecnistas brasileiros e seu pensamento estratégico referente ao futuro desta profissão.

\section{A Fundação da Associação Brasileira de Zootecnistas}

Em 24 de setembro de 1988, na Faculdade de Medicina Veterinária e Zootecnia da USP, uma assembléia presidida pelo Zootecnista Mateus José Rodrigues Paranhos da Costa, decidiu pela fundação de uma entidade para os zootecnistas de todo o país, a Associação Brasileira de Zootecnistas (ABZ).

Até hoje, quatro presidentes passaram pela ABZ. O primeiro, e também fundador, foi o Zootecnista Luiz Augusto Müller (RS), tendo sido sucedido por Jorge Luiz Correia de Oliveira (SP) e Marcos Elias Traad da Silva (PR). Atualmente, a ABZ é presidida por Severino Benone Paes Barbosa (PE). 
Em que pese o fato de uma entidade associativa profissional dedicar-se prioritariamente aos aspectos das relações sociais de seus membros, bem como primar pela necessidade de aprimoramento contínuo da profissão pela oferta de cursos e programas de treinamento em diferentes níveis aos seus profissionais, a ABZ sempre se apresentou como articuladora de ações da esfera sindical e política, isso em função de alguns aspectos de relevância. Primeiro, pela falta de uma entidade nacional com essa incumbência, a exemplo do que executam as federações e as confederações nacionais representativas de diferentes classes e categorias profissionais. Segundo, pela necessidade de melhor organização dos profissionais nos diferentes estados, tendo em vista que, desde a gestão do Zootecnista Jorge Luiz Correia de Oliveira como Presidente da entidade, foram estabelecidos os Fóruns Nacionais de Entidades de Zootecnistas. Tais fóruns sempre foram realizados com certa periodicidade e com a freqüência sempre expressiva de presidentes de sindicatos, associações estaduais, representantes de Zootecnistas nos conselhos de Medicina Veterinária e, mais recentemente (mais precisamente a partir de 1997), com a participação dos representantes de centros acadêmicos e diretórios estudantis das Instituições de Ensino de Zootecnia de todo o país.

\section{O Zootec}

Decididamente, procurando estruturar seu espaço no ambiente técnico e científico no contexto da moderna Zootecnia nacional, a ABZ passou a envidar esforços para garantir a continuidade dos eventos científicos que vinha realizando sem a necessária constância e profissionalismo. A partir de 1997, houve a realização do VII Congresso Brasileiro de Zootecnia, entre os dias 26 e 28 de maio, na Universidade Federal de Minas Gerais, em Belo Horizonte (MG), doravante denominado de ZOOTEC, por sugestão do Zootecnista, Professor Walter Motta Ferreira, primeiro presidente do ZOOTEC. A nova configuração do evento permitia a simultaneidade do Congresso Brasileiro e ou Internacional de Zootecnia, Reunião Nacional de Ensino da Zootecnia e Fórum Nacional de Entidades de Zootecnistas. Naquela ocasião, reuniramse 400 participantes, num evento que induziu ao início da profissionalização do Congresso Brasilei- ro de Zootecnia organizado pela ABZ. Esse passou inclusive a ocupar espaço importante no calendário nacional de eventos da agropecuária. Foi a partir daquele mesmo ponto que a $\mathrm{ABZ}$ passou a ser a promotora oficial do congresso, sendo, por esse motivo, mais reconhecida pelos Zootecnistas brasileiros. Atualmente, o público do ZOOTEC supera os mil participantes provenientes de diversas partes do país e do exterior, consolidando o caráter técnico e científico da Zootecnia e a sua importância como profissão que promove o desenvolvimento do agronegócio como um todo.

\section{Diretrizes curriculares nacionais para os cursos de graduação em Zootecnia}

A construção das Diretrizes Curriculares para a Zootecnia antecede ao chamamento feito pelo Edital n. ${ }^{\circ} 4$ da SESu/MEC, datado de 10/12/1997. A iniciativa de discussão do currículo mínimo, balizador dos cursos, inicia-se com a "Primeira Reunião Nacional de Ensino de Zootecnia", realizada em 1993 na UFRRJ, quando se reuniram os dirigentes e coordenadores de cursos de todo o Brasil imbuídos da proposta de reavaliação das estruturas curriculares em vigor. Anualmente, a partir de 1994, nas plenárias da Comissão Técnica de Zootecnia da Associação Brasileira de Educação Agrícola Superior (ABEAS), e de 1996, nas Reuniões Nacionais de Ensino de Zootecnia realizadas nos ZOOTEC, este assunto esteve sempre na pauta de discussões.

Dessa forma, em junho de 1998, em atendimento ao Edital $n^{\circ} 4$, os zootecnistas brasileiros encaminharam a primeira versão das Diretrizes Curriculares à Comissão de Especialistas de Ciências Agrárias da Secretaria de Educação Superior (CECA/ SESu) do MEC, sob coordenação da então Comissão Nacional de Ensino de Zootecnia (CNEZ) do Conselho Federal de Medicina Veterinária (CFMV) e da Associação Brasileira de Zootecnistas (ABZ), que passaram a ser os interlocutores desse processo junto à SESu e, posteriormente, junto ao Conselho Nacional de Educação.

O CNE indicou o conselheiro Roberto Cláudio Frota Bezerra para relatar estas Diretrizes Curriculares. A partir de 2001, a CNEZ e a ABZ começaram a dialogar com o relator, na tentativa de sensibilizá-lo quanto ao equívoco de se constituírem Diretrizes Curriculares comuns para cursos tão distintos, com a argumentação de que existem áreas de con- 
fluência entre o exercício profissional da Zootecnia com o da Agronomia e Veterinária e isso, por si só, justificaria a existência de definições de Diretrizes Curriculares individualizadas, claras e objetivas, por curso. Além disso, existem diferenças gritantes entre a formação de Engenheiros Agrícolas, Engenheiros Florestais e Engenheiros de Pesca que levam, por uma questão de bom senso, a pensar que é inconcebível a existência de um único documento de Diretrizes Curriculares para nortear a formação de profissionais dessas áreas e da Zootecnia, conjuntamente.

O relator concordou com a necessidade da separação das Diretrizes e abriu mais um prazo para encaminhamento das propostas pelos diferentes cursos.

Os aprimoramentos resultaram em uma nova versão das Diretrizes Curriculares Nacionais dos cursos de graduação em Zootecnia, já conformada como uma minuta de resolução específica. Esta proposta foi encaminhada, em julho de 2002, ao CNE e acolhida com entusiasmo pelo relator desta matéria.

Embora estivesse prevista uma definição deste processo no CNE para novembro de 2002, recebeu-se a notícia de que o Conselho Federal da Ordem dos Advogados do Brasil (OAB) obteve liminar junto ao Poder Judiciário, suspendendo até o julgamento do mérito, os encaminhamentos das Diretrizes Curriculares de todos os cursos.

Após grande expectativa e diversas ações no âmbito da ABZ e por parte dos zootecnistas, foram aprovadas as Diretrizes Curriculares Nacionais dos Cursos de Graduação em Zootecnia (parecer CES 337/04) pelo CNE (D.O.U. de 29 de dezembro de 2004, seção 1, página 269) contemplando a proposta encaminhada pela comunidade acadêmica. A homologação pelo Excelentíssimo senhor Ministro da Educação deu-se em 17 de dezembro de 2004 (D.O.U. de 20 de dezembro de 2004, número 243, seção 1, página 29). Finalmente, as Diretrizes Curriculares foram definidas pela Resolução número 4 de 02 de fevereiro de 2006, publicada no D.O.U. número 25 , de 03 de fevereiro de 2006, seção 1, páginas 34 e 35 (Anexo 1).

A aprovação das Diretrizes Curriculares para os cursos de Graduação em Zootecnia, já concretizada, inclina-nos ao árduo trabalho de sua implementação nas IES mantenedoras do ensino de Zootecnia e que deve suscitar importante esforço do Fórum de Coordenadores de Cursos, tanto para a adequação como para a reformulação curricular exigida.

\section{Referências}

BOURDIEU, P. Razões práticas: sobre a teoria da acção. Oeiras: Celta, 1997.

CAPDEVILLE, G. O ensino superior agrícola no Brasil. Viçosa: Universidade Federal de Viçosa, 1991. 184p.

GAGNE, R. Campos de aprendizaje. In: GAGNÉ, R.; BRIGGS, R. La planificación de la enseñanza. Trillas, 1976. p 109-116.

GARCIA, L. A. M. Competências e habilidades: você sabe lidar com isso? Disponível em: <http:/ /www.educacaopublica.rj.gov.br/biblioteca/ educacao/educ23g.htm>. Acesso em: 08 mar. 2005.

INEP - Instituto Nacional de Pesquisas e Estudos Educacionais. Resultados e Tendências da Educação Superior. INEP - MEC, Brasília, DF: 2000. $68 \mathrm{p}$.

INEP - Instituto Nacional de Pesquisas e Estudos Educacionais. Sinopse Estatística da Educação Superior 2000. INEP - MEC, Brasília, DF: 2001. $400 \mathrm{p}$.

INEP - Instituto Nacional de Pesquisas e Estudos Educacionais. Sinopse Estatística da Educação Superior 2004. INEP - MEC, Brasília, DF: 2004.

KNIGHT, J. Trade in higher education services: the implications of GATS. Kagisano Issue, v. 3, p. 5 37, 2003.

MEHTA, L. The World Bank and its emerging knowledge empire. Human Organization, v. 60, n. 2, p. 189 -196, 2001.

PACHECO, J.A. Competências curriculares: as práticas ocultas nos discursos das reformas. Universidade do Minho. Minho, Portugal: Manuscrit 2003.

PACHECO, J. A.; FLORES, M. Formação e avaliação de professores. Porto,: [S. n.],1999.

SILVA, M. E. T. Desempenho de búfalos (Bubalus bubalis L.) confinados em terminação, com dietas contendo diferentes relações de volumoso e concentrado. 1997. 115 f. Dissertação (Mestrado) Universidade Federal do Paraná, Curitiba, 1997.

Recebido: 05/08/2005 Aprovado: 20/12/2005 